\title{
The current obstetrical and perinatal management of congenital diaphragmatic hernia
}

\author{
Managementul obstetrical și perinatal actual al herniei diafragmatice \\ congenitale
}

\begin{abstract}
Bianca Mihaela DANCIU ${ }^{1}$, Vlad DIMA², Dora BOGHIȚOIU ${ }^{3,4}$, Ana Maria Alexandra STĂNESCU ${ }^{5}$, Anca Angela SIMIONESCU 6,7

${ }^{1}$ Obstetrică-Ginecologie, Institutul Naţional pentru Sănătatea Mamei şi Copilului „Alessandrescu-Rusescu“, Bucureşti, România

${ }^{2}$ Neonatologie, Spitalul Clinic Filantropia, Bucureşti, România ${ }^{3}$ Spitalul Clinic de Urgenţă pentru Copii „Grigore Alexandrescu”, Bucureşti, România ${ }^{4}$ Pediatrie, Universitatea de Medicină şi Farmacie "Carol Davila“, Bucureşti, România ${ }^{5}$ Medicină de familie, Universitatea de Medicină şi Farmacie „Carol Davila“, Bucureşti, România ${ }^{6}$ Obstetrică-Ginecologie, Universitatea de Medicină şi Farmacie „Carol Davila“, Bucureşti, România ${ }^{7}$ Obstetrică-Ginecologie, Spitalul Clinic Filantropia, Bucureşti, România
\end{abstract}

\begin{abstract}
Congenital diaphragmatic hernia is a severe condition with an etiology and pathogenesis still been developed; also, the involvement of genetic and environmental factors in the occurrence of this malformation is under study. Morbi-mortality in these patients is high, and quality of life is diminished. Under these circumstances, careful follow-up of the pregnancy and multidisciplinary management after birth is needed to diagnose the malformation as early as possible and adapt the therapeutic plan to the particularities of each case. In conclusion, despite several research data in the literature concerning this topic, the management of newborn babies with congenital diaphragmatic hernia remains a severe challenge. The treatment of congenital diaphragmatic hernia remains the prerogative of overqualified teams.
\end{abstract}

Keywords: congenital diaphragmatic hernia, Bochdalek hernia, Morgagni hernia

\section{REZUMAT}

Hernia diafragmatică congenitală este o afecțiune severă, cu o etiologie și o patogeneză care sunt încă studiate, ca şi implicarea factorilor genetici și a celor de mediu în apariția acestei malformații. De asemenea, pe termen lung, complicațiile sunt numeroase, iar calitatea vieții este diminuată. Astfel, se recomandă o urmărire atentă a sarcinii și o decizie terapeutică multidisciplinară după naștere, pentru a diagnostica cât mai precoce malformația și a adapta cât mai corespunzător planul terapeutic la particularitățile cazului. In ceea ce privește tehnicile intervenționale, abordarea in utero a patologiei este deja frecvent utilizată, îmbunătățiri ale metodei fiind deopotrivă studiate. În concluzie, în ciuda numeroaselor cercetări pe această 
temă, managementul nou-născutului cu hernie diafragmatică congenitală rămâne încă o provocare, iar rata de mortalitate și morbiditate în rândul acestora rămâne ridicată. Tratamentul herniei congenitale diafragmatice rămîne apanajul echipelor supraspecializate.

Cuvinte cheie: hernie diafragmatică congenitală, hernie Bochdalek, hernie

\section{INTRODUCERE}

Hernia diafragmatică congenitală este o malformație întâlnită la 2,3-2,8 din 10.000 de nou-născuți vii [1-4]. Aproximativ $30 \%$ dintre aceștia nu supraviețuiesc, în ciuda îngrijirii neonatale adecvate și a eforturilor terapeutice multidisciplinare [5]. Hernia diafragmatică congenitală apare din cauza dezvoltării incomplete a diafragmului, prin tulburări de embriogeneză, astfel fiind posibilă protruzia conținutului abdominal în cavitatea toracică. În urma ascensionării elementelor abdominale și a ocupării spațiului toracic de către acestea, este afectată și dezvoltarea plămânilor, cu efecte mai importante cu cât hernierea are loc mai devreme în dezvoltarea embriologică [6].

Nou-născuții prezintă hipoplazie pulmonară prin afectarea morfogenezei ramificării sistemului tubular pulmonar, hipoplazie acinară, alveolizare diminuată, îngroșarea pereților alveolari și afectarea dezvoltării bronșiolelor terminale [7-9]. În urma acestor modificări structurale, se dezvoltă hipertensiune intrapulmonară prin remodelare vasculară, scăderea în dimensiuni a patului vascular pulmonar și reactivitate alterată [8]. Aceste cazuri prezintă procentul de mortalitate cel mai ridicat atât în timpul vieții intrauterine, cât și după naștere [8].

Se descrie o clasificare a herniei diafragmatice congenitale, în funcție de localizare, astfel $[7,8]$ : hernii diafragmatice cu localizare pe partea stângă (85-90\% dintre cazuri); hernii diafragmatice cu localizare pe partea dreaptă (10-15\% dintre cazuri).

În ceea ce privește porțiunea anatomică afectată, se prezintă $[7,8]$ : hernia Bochdalek, defect posterolateral al diafragmului (70\% dintre cazuri); hernia Morgagni, defect anteromedial al diafragmului (27\% dintre cazuri); defecte bilaterale ( $3 \%$ dintre cazuri), foarte rare, întâlnite cel mai frecvent la necropsii [9-11].

Nou-născuții prezintă adesea hipertensiune pulmonară persistentă, reflux gastroesofagian, dificultăți în alimentație și, implicit, tulburări de creștere, boală pulmonară cronică, întârziere în dezvoltarea neurocognitivă, deformări toracice și pierderea auzului [12].

\section{DIAGNOSTIC}

Diagnosticul herniei diafragmatice congenitale prin semne directe se face, în general, ultrasonografic, în trimestrul al doilea, între $24[4,13]$ și 27 de săptămâni [14].

Se urmăresc anumiți parametri, în funcție de care poate fi definită și clasificată patologia, dar se poate oferi și un prognostic provizoriu:dimensiunile pulmonare, hipertensiunea pulmonară, poziția stomacului, poziția ficatului.

Semnele directe ultrasonografice de diagnostic sunt prezența structurilor abdominale în cavitatea toracică, iar cele indirecte - polihidramnios, axul cardiac deplasat anormal, modificări la nivel mediastinal [15].

Referitor la hernia diafragmatică dreaptă, rata de supraviețuire în aceste cazuri este de numai $53 \%$, reprezentând o condiție mult mai severă [16]. În aceste cazuri, parametrii ecografici se modifică și hernierea ficatului nu mai influențează prognosticul, fiind prezentă în majoritatea cazurilor.

Din punct de vedere genetic, există numeroase asocieri caracteristice herniei diafragmatice congenitale (Tabelul 1).

Patogeneza acestor malformații este intens combătută. Sunt studii conform cărora factorii de mediu și căile de semnalizare specifice constituie factorii declanșatori ai malformației diafragmatice [29]. Etiologia herniei diafragmatice congenitale este pusă și pe seama căii de semnalizare a retinoizilor, fiind descrise implicații ale deficitului de vitamină A în embriogeneză $[33,34]$.

\section{MANAGEMENT ANTENATAL}

Strategiile terapeutice ce vizează îmbunătățirea hipoplaziei și a hipertensiunii pulmonare au indicația să fie începute cât mai precoce, încă din viața intrauterină.

În ceea ce privește administrarea medicației corticoide, nu există studii semnificative conform cărora administrarea prenatală a acesteia poate să îmbunătățească semnificativ evoluția postnatală. Cu toate acestea, recent, medicația corticoidă $\mathrm{s}$-a administrat la vârste gestaționale mai mici de 37 de săptămâni, mai exact între 34 și 36 de săptămâni, fiind asociată cu scăderea necesității asigurării de suport respirator postpartum [35]. Pe lângă efectul benefic, betametazona a fost asociată cu risc crescut de hipoglicemie neonatală.

Prin prisma efectului etiopatogenic al căii de semnalizare a retinoizilor, a fost testat efectul administrării de retinoizi asupra hipoplaziei pulmonare. Rămâne dificil de spus dacă beneficiile pe care aceștia le aduc 
TABEL 1. Sindroame genetice, cromozomiale și anomalii structurale asociate cu hernia diafragmatică congenitală [17-19, 21-23, 26-32]

\begin{tabular}{|l|l|l|}
\hline Sindroame genetice & Anomalii genetice și cromozomiale & Anomalii structurale \\
\hline Sindromul Beckwith-Wiedemann & Trisomia 13 & Defectul de sept ventricular \\
\hline Sindromul Brachman de Lange & Tetrasomia 9 p & Defectul de sept atrial \\
\hline Sindroul CHARGE & Trisomia 18 & Tetralogia Fallot \\
\hline Sindromul Cornelia de Lange & Trisomia 21 & Coarctația de aortă \\
\hline Sindromul craniofrontonazal & Monosomia X & Inelele vasculare \\
\hline Sindromul Denys-Drash & Tetrasomia 12p & Defecte de tub neural \\
\hline Sindromul Donnai-Barrow & Sindromul de deleție 8p23.1 & Hidrocefalie \\
\hline Sindromul Fryns & Sindromul de deleție 15q26.1 & Defecte de dezvoltare ale membrelor \\
\hline Sindromul Ghersoni-Baruch & Sindromul de deleție 15 q 24-26 & Polidactilie \\
\hline Sindromul Pallister-Killian & Sindromul de deleție 1q41-42 & Sindactilie \\
\hline Sindromul Simpson-Golabi-Behmel & Deleția 8q23.1 & \\
\hline Sindromul toraco-abdominal & Deleția 4p16 & \\
\hline Sindromul Wolf-Hirschhorn & Duplicația 11q23.2 & \\
\hline \\
CHARGE-acronim pentru colobom, malformații cardiace, atrezie conală, restricție de creștere, anomalii în dezvoltarea organelor \\
genitale și defecte de formare ale urechilor
\end{tabular}

depășesc semnificativ efectele teratogenice datorate toxicității retinoide [36,37].

Administrarea de inhibitori de fosfodiesterază oferă cele mai bune rezultate, demonstrându-și eficacitatea în numeroase studii. Sildenafilul este deja frecvent folosit în tratamentul hipertensiunii pulmonare neonatale. Este recunoscut efectul benefic al acestui tratament asupra vascularizației pulmonare, demonstrându-și și siguranța administrării, dar și eficacitatea terapeutică [38].

Din punct de vedere intervențional, in utero, se poate realiza ocluzia traheei prin FETO (fetoscopic endoluminal tracheal occlusion), ceea ce s-a demonstrat științific că se asociază cu hiperplazie pulmonară. Această intervenție se realizează între 27 și 32 de săptămâni, ținând cont și de particularitățile malformației. Dezobstrucția traheală este necesar să fie realizată tot intrauterin, cu câteva săptămâni înainte de naștere, pentru a putea permite maturarea pulmonară $[39,40]$. Procedura a fost dezvoltată pe parcursul a 31 de ani, în prezent fiind necesară doar plasarea unui clip, minimum invaziv, printr-o procedură percutană sono-endoscopică $[41,42]$. Nu este necesară anestezia generală, fiind suficientă anestezia regională cu analgezie fetală. Intervenția durează în general aproximativ 10 minute, minimizând riscul de rupere prematură de membrane, acesta fiind și cel mai frecvent efect advers al intervenției [43].

\section{MANAGEMENT PERINATAL}

Referitor la momentul și tipul nașterii, studiile sunt controversate, dar este recomandată nașterea cât mai aproape de termen, fără inducerea acesteia înainte de 38 de săptămâni. Nici operația cezariană electivă nu este indicată, singurul consens fiind că este recoman- dat ca nașterea să aibă loc într-un centru specializat, echipat cu aparatură de terapie intensivă neonatală $[44,45]$.

\section{MANAGEMENT POSTNATAL}

Imediat după naștere, după ce a fost preluat de serviciul de neonatologie, nou-născutului i se alege tehnică de ventilație optimă [46]. În general, este indicată intubarea cât mai repede posibil, pentru a evita risipirea aerului prin efortul respirator de a insufla stomacul și intestinul subțire. Trebuie ținut cont și de faptul că, la nou-născuții cu hernie diafragmatică congenitală, poziția carinei este mai ridicată decât normal și astfel e necesară adaptarea profunzimii la care este introdusă sonda endotraheală cu aproximativ $0,5 \mathrm{~cm}$ [47]. Actualmente, se studiază evoluția feților la care procedurile de resuscitare au început înainte de a clampa cordonul ombilical [48]. Este indicată monitorizarea ritmului cardiac, a presiunii arteriale și saturațiile pre și postductale [49]. După intubare, este recomandată montarea unei sonde orogastrice.

Ventilația va fi ghidată după principiul descris de Wung în 1985 [50], conform căruia este permisă hipercapnia cu ventilație, ce menține saturații preductale între 80 și 95\%, iar cele postductale peste $70 \%$, iar presiunea parțială a dioxidului de carbon între 50 și $70 \mathrm{~mm}$ $\mathrm{Hg}[49,51,52]$. Recomandările actuale sunt de inițiere de presiune intermitent pozitivă (PIP) sub $25 \mathrm{~cm} \mathrm{H}_{2} \mathrm{O}, 0$ presiune pozitivă la sfârșitul expirului (PEEP) de $3-5 \mathrm{~cm}$ $\mathrm{H}_{2} \mathrm{O}$ și o rată de $40-60$ de respirații pe minut, menținând $\mathrm{PaCO}_{2}$ între 50 și 70 mm Hg [49,52,53]. Din momentul în care nu se poate menține o ventilație cu PIP de $30 \mathrm{~cm}$ $\mathrm{H}_{2} \mathrm{O}$ și o rată de 60 de respirații pe minut, este recomandată inițierea ventilației oscilatorii de înaltă frecvență (HFOV), cu presiune medie a căilor respirato- 
rii între 14 și 16 cm H $\mathrm{H}_{2} \mathrm{O}$ [52-55]. Când nici această presiune medie nu mai poate fi întreținută, se recomandă inițierea oxigenării extracorporeale cu membrană (ECMO). Valoarea pH-ului este vitală în aceste cazuri și e indicat să fie menținută în parametri normali.

Managementul hemodinamic se realizează prin ECMO, resuscitare volumică prin soluții cristaloide, vasopresoare ca dopamina și epinefrina [49]. Uneori, sunt necesari și corticoizii pentru stabilizare hemodinamică [56-58].

După stabilizare, se recomandă intervenția chirurgicală de reparare a defectului diafragmatic și de reducere a hernierii structurilor abdominale. Se recomandă evitarea primelor 12-36 de ore după naștere, când nounăscutul compensează adecvat, fiind stabil hemodinamic și realizând schimburile gazoase corect, fiind urmată de o deteriorare progresivă respiratorie [59]. Intervențiile chirurgicale realizate în această perioadă au avut rezultate nesatisfăcătoare și s-a stabilit recomandarea temporizării acestor intervenții, dacă este posibil [60-64]. În funcție de dimensiunile defectului, se poate opta pentru sutură per primam cu închiderea primară a defectului, dar când dimensiunea defectului este mare există opțiuni de material prostetic (GoreTex, Flagstaff, AZ) sau lambou al mușchiului transvers abdominal, cel din urmă având cele mai mici rate de recurență sau de infecție postoperatorie [65].

Există și varianta toracoscopică a intervenției, dar care prezintă risc mare de recurență postintervențional. Această metodă nu mai este utilizată la scară largă și se recomandă reintroducerea sa în studii clinice pentru a determina cu exactitate cazurile în care este indicată utilizarea sa [44].

Sunt în studiu și tratamente ale herniei diafragmatice ce folosesc celule stem mezenchimale, injectate in- traamniotic la nivel fetal, ce s-a demonstrat că au crescut numărul de alveole, au lărgit spațiile respiratorii și au subțiat pereții alveolari. Momentan, aceste studii sunt realizate pe șobolani, dar, ținând cont de rezultatele pozitive, este previzibil ca în viitorul apropiat să se poată aplica și pentru oameni [66].

Tot la stadiul de teste este și crearea unui nou tip de balon pentru intervențiile in utero, necesitatea acestuia fiind întărită de complicațiile obstetricale asociate cu FETO. Acest nou dispozitiv utilizează o valvă metalică la capătul proximal al balonului. Valva este compusă dintr-o bilă magnetică, ce se află în interiorul balonului și în imediata apropiere a unui cilindru metalic. Se instilează soluție salină la nivelul valvei, iar prin forța hidraulică bila este deplasată distal și, astfel, balonul se umflă. După ce s-a umflat balonul, bila alunecă înapoi în cilindrul metalic și balonul rămâne pe poziția umflat. Pentru a reduce stenoza traheală, înainte de naștere, se utilizează RMN-ul, care, cu ajutorul câmpului magnetic format, modifică poziția bilei astfel încât balonul să se poată dezumfla. Apoi, acesta este eliminat fiziologic din trahee, cu ajutorul recirculării lichidului amniotic, nefiind necesară o intervenție ulterioară, cu riscurile asociate [67].

Noile tehnici de management ale herniei congenitale diafragmatice au crescut rata de supraviețuire la 70$90 \%$ în centrele ultraspecializate pentru nou-născuții care nu necesită ECMO și 50\% pentru cei care necesită ECMO $[68,69]$.

\section{CONCLUZIE}

Tratamentul herniei congenitale diafragmatice rămîne apanajul echipelor supraspecializate, cu cazuistică și echipamente de înaltă performanță.

Conflict of interest: none declared Financial support: none declared

\section{BIBLIOGRAFIE}

1. McGivern MR, Best KE, Rankin J, et al. Epidemiology of congenital diaphragmatic hernia in Europe: a register-based study. Arch Dis Child Fetal Neonatal Ed. 2015;100(2):F137-144.

2. Wright JC, Budd JL, Field DJ, et al. Epidemiology and outcome of congenital diaphragmatic hernia: a 9-year experience. Paediatr Perinat Epidemiol. 2011; 25(2):144-149.

3. Parker SE, Mai CT, Canfield MA, et al. National Birth Defects Prevention Network. Updated National Birth Prevalence estimates for selected birth defects in the United States, 2004-2006. Birth Defects Res A Clin Mol Teratol. 2010;88(12):1008-1016.
4. Garne E, Haeusler M, Barisic I, et al. Euroscan Study Group. Congenital diaphragmatic hernia: evaluation of prenatal diagnosis in 20 European regions. Ultrasound Obstet Gynecol. 2002; 19(4):329-333.

5. Harting MT, Lally KP. The Congenital Diaphragmatic Hernia Study Group registry update. Semin Fetal Neonatal Med. 2014;19(6):370-375.

6. Keijzer R, Liu J, Deimling J, et al. Dual-hit hypothesis explains pulmonary hypoplasia in the nitrofen model of congenital diaphragmatic hernia. Am J Pathol. 2000;156(4):1299-1306.
7. George DK, Cooney TP, Chiu BK, et al. Hypoplasia and immaturity of the terminal lung unit (acinus) in congenital diaphragmatic hernia. Am Rev Respir Dis. 1987;136(4):947-950.

8. Kitagawa M, Hislop A, Boyden EA, et al. Lung hypoplasia in congenital diaphragmatic hernia. A quantitative study of airway, artery, and alveolar development. Br J Surg. 1971;58(5):342-346.

9. Mukthapuram S, Beebe J, Tkach JA, et al. MRI Assessment of Pulmonary Vascularity in Infants With Congenital Diaphragmatic Hernia: A Novel Tool for Direct Assessment of Severity of Pulmonary Hypertension and 
Hypoplasia. J Pediatr. 2021;S00223476(21)00751-4.

10. Irish MS, Holm BA, Glick PL. Congenital diaphragmatic hernia. A historical review. Clin Perinatol. 1996;23(4):625-653.

11. Brownlee EM, Howatson AG, Davis CF, et al. The hidden mortality of congenital diaphragmatic hernia: a 20-year review. J Pediatr Surg. 2009;44(2):317-320.

12. American Academy of Pediatrics Section on Surgery; American Academy of Pediatrics Committee on Fetus and Newborn, Lally KP, Engle W. Postdischarge follow-up of infants with congenital diaphragmatic hernia. Pediatrics. 2008;121(3):627-632.

13. Alfaraj MA, Shah PS, Bohn D, et al. Congenital diaphragmatic hernia: lung-tohead ratio and lung volume for prediction of outcome. Am J Obstet Gynecol. 2011; 205(1):43.e1-8.

14. Gallot D, Boda C, Ughetto S, et al. Prenatal detection and outcome of congenital diaphragmatic hernia: a French registrybased study. Ultrasound Obstet Gynecol. 2007; 29(3):276-283.

15. Graham G, Devine PC. Antenatal diagnosis of congenital diaphragmatic hernia. Semin Perinatol. 2005;29(2):69-76.

16. DeKoninck P, Gomez O, Sandaite I, et al.Right-sided congenital diaphragmatic hernia in a decade of fetal surgery. BJOG. 2015;122(7):940-946.

17. Martínez-Frías ML, Bermejo E, Félix V, et al. Brachmann-de-Lange syndrome in our population: clinical and epidemiological characteristics. An Esp Pediatr. 1998; 48(3):293-298.

18. Kantarci S, Donahoe PK. Congenital diaphragmatic hernia $(\mathrm{CDH})$ etiology as revealed by pathway genetics. Am J Med Genet C Semin Med Genet. 2007; $145 \mathrm{C}(2): 217-226$.

19. van Dooren MF, Brooks AS, Hoogeboom AJ, et al. Early diagnosis of Wolf-Hirschhorn syndrome triggered by a life-threatening event: congenital diaphragmatic hernia. Am J Med Genet A. 2004;127A(2):194-196.

20. Blancato JK, Hunt M, George J, et al. Prenatal diagnosis of tetrasomy $12 p$ by in situ hybridization: varying levels of mosaicism in different fetal tissues. Prenat Diagn. 1992;12(12):979-983.

21. Klaassens M, Scott DA, van Dooren M, et al.Congenital diaphragmatic hernia associated with duplication of 11q23-qter Am J Med Genet A. 2006;140(14):15801586.

22. Schlembach D, Zenker M, Trautmann U, et al. Deletion 15q24-26 in prenatally detected diaphragmatic hernia: increasing evidence of a candidate region for diaphragmatic development. Prenat Diagn. 2001; 21(4):289-292.

23. Biggio JR Jr, Descartes MD, Carroll AJ, et al. Congenital diaphragmatic hernia: is $15 q 26.1$ 26.2 a candidate locus? Am J Med Genet $A$. 2004;126A(2):183-185.

24. Kantarci S, Ackerman KG, Russell MK, et al. Characterization of the chromosome $1 q 41 q 42.12$ region, and the candidate gene
DISP1, in patients with CDH. Am J Med Genet A. 2010;152A(10):2493-2504.

25. McPherson EW, Ketterer DM, Salsburey DJ. Pallister-Killian and Fryns syndromes: nosology. Am J Med Genet. 1993; 47(2):241-245

26. Franceschini P, Guala A, Licata D, et al. Gershoni-Baruch syndrome: report of a new family confirming autosomal recessive inheritance. Am J Med Genet A. 2003;122A(2):174-179.

27. Scott DA, Cooper ML, Stankiewicz P, et al. Congenital diaphragmatic hernia in WAGR syndrome. Am J Med Genet A. 2005;134(4):430-433.

28. Cho HY, Lee BS, Kang $\mathrm{CH}$ et al.Hydrothorax in a patient with Denys-Drash syndrome associated with a diaphragmatic defect. Pediatr Nephrol. 2006;21(12):1909-1912.

29. Holder AM, Klaassens M, Tibboel D, et al. Genetic factors in congenital diaphragmatic hernia. Am J Hum Genet. 2007 May;80(5):825-845.

30. Chatterjee D, Ing RJ, Gien J. Update on Congenital Diaphragmatic Hernia. Anesth Analg. 2020;131(3):808-821.

31. Pober BR. Genetic aspects of human congenital diaphragmatic hernia. Clin Genet. 2008;74(1):1-15.

32. Enns GM, Cox VA, Goldstein RB, et al. Congenital diaphragmatic defects and associated syndromes, malformations, and chromosome anomalies: a retrospective study of 60 patients and literature review. Am J Med Genet. 1998;79(3):215-225.

33. Kling DE, Schnitzer JJ. Vitamin A deficiency (VAD), teratogenic, and surgical models of congenital diaphragmatic hernia (CDH). Am J Med Genet C Semin Med Genet. 2007; 145C(2):139-157.

34. Greer JJ, Babiuk RP, Thebaud B. Etiology of congenital diaphragmatic hernia: the retinoid hypothesis. Pediatr Res. 2003; 53(5):726-730.

35. Roberts D, Brown J, Medley N, et al. Antenatal corticosteroids for accelerating fetal lung maturation for women at risk of preterm birth. Cochrane Database Syst Rev. 2017;3(3):CD004454. Update in: Cochrane Database Syst Rev. 2020 Dec 25;12:CD004454.

36. Coste K, Beurskens LW, Blanc P, et al. Metabolic disturbances of the vitamin $\mathrm{A}$ pathway in human diaphragmatic hernia. Am J Physiol Lung Cell Mol Physiol. 2015;308(2):L147-157.

37. Montedonico S, Nakazawa N, Puri P. Congenital diaphragmatic hernia and retinoids: searching for an etiology. Pediatr Surg Int. 2008;24(7):755-761.

38. Noori S, Friedlich $\mathrm{P}$, Wong $\mathrm{P}$, et al. Cardiovascular effects of sildenafil in neonates and infants with congenital diaphragmatic hernia and pulmonary hypertension. Neonatology. 2007; 91(2):92-100.

39. Carmel Ja, Friedman F, Adams FH. Fetal Tracheal Ligation And Lung Development. Am J Dis Child. 1965;109:452-456.
40. Flageole H, Evrard VA, Piedboeuf B, et al. The plug-unplug sequence: an important step to achieve type II pneumocyte maturation in the fetal lamb model. $J$ Pediatr Surg. 1998;33(2):299-303.

41. VanderWall KJ, Bruch SW, Meuli M, et al. Fetal endoscopic ('Fetendo') tracheal clip. J Pediatr Surg. 1996;31(8):1101-1103.

42. Flake AW, Crombleholme TM, Johnson MP, et al. Treatment of severe congenital diaphragmatic hernia by fetal tracheal occlusion: clinical experience with fifteen cases. Am J Obstet Gynecol. 2000;183(5):1059-1066.

43. Jani JC, Nicolaides KH, Gratacós E, et al. Severe diaphragmatic hernia treated by fetal endoscopic tracheal occlusion. Ultrasound Obstet Gynecol. 2009;34(3):304-310.

44. Canadian Congenital Diaphragmatic Hernia Collaborative, Puligandla PS, Skarsgard ED, Offringa M, Adatia I, et al. Diagnosis and management of congenital diaphragmatic hernia: a clinical practice guideline. CMAJ. 2018 Jan 29;190(4):E103-E112.

45. Safavi A, Lin Y, Skarsgard ED; Canadian Pediatric Surgery Network. Perinatal management of congenital diaphragmatic hernia: when and how should babies be delivered? Results from the Canadian Pediatric Surgery Network. J Pediatr Surg. 2010;45(12):2334-2339.

46. American Heart Association. 2005 American Heart Association (AHA) guidelines for cardiopulmonary resuscitation (CPR) and emergency cardiovascular care (ECC) of pediatric and neonatal patients: pediatric basic life support. Pediatrics. 2006; 117(5):e989-1004.

47. Gien J, Meyers ML, Kinsella JP. Assessment of Carina Position Antenatally and Postnatally in Infants with Congenital Diaphragmatic Hernia. J Pediatr. 2018;192:93-98.e1.

48. Lefebvre C, Rakza T, Weslinck N, et al. Feasibility and safety of intact cord resuscitation in newborn infants with congenital diaphragmatic hernia (CDH). Resuscitation. 2017;120:20-25.

49. Snoek KG, Reiss IK, Greenough A, et al. CDH EURO Consortium. Standardized Postnatal Management of Infants with Congenital Diaphragmatic Hernia in Europe: The CDH EURO Consortium Consensus 2015 Update. Neonatology. 2016; 110(1):66-74.

50. Wung JT, James LS, Kilchevsky E, et al. Management of infants with severe respiratory failure and persistence of the fetal circulation, without hyperventilation. Pediatrics. 1985;76(4):488-494.

51. Logan JW, Rice HE, Goldberg RN, et al. Congenital diaphragmatic hernia: a systematic review and summary of best-evidence practice strategies. J Perinatol. 2007;27(9):535-549.

52. Logan JW, Cotten CM, Goldberg RN, et al.Mechanical ventilation strategies in the management of congenital diaphragmatic hernia. Semin Pediatr Surg. 2007;1 6(2):115-125. 
53. Puligandla PS, Grabowski J, Austin M, et al. Management of congenital diaphragmatic hernia: A systematic review from the APSA outcomes and evidence based practice committee. J Pediatr Surg. 2015;50(11):1958-1970.

54. Desfrere L, Jarreau PH, Dommergues M, et al. Impact of delayed repair and elective high-frequency oscillatory ventilation on survival of antenatally diagnosed congenital diaphragmatic hernia: first application of these strategies in the more "severe" subgroup of antenatally diagnosed newborns. Intensive Care Med. 2000;26(7):934-941.

55. Somaschini M, Locatelli G, Salvoni L, et al. Impact of new treatments for respiratory failure on outcome of infants with congenital diaphragmatic hernia. Eur J Pediatr. 1999;158(10):780-784.

56. Pittinger TP, Sawin RS. Adrenocortical insufficiency in infants with congenital diaphragmatic hernia: a pilot study. J Pediatr Surg. 2000;35(2):223-225.

57. Kamath BD, Fashaw L, Kinsella JP. Adrenal insufficiency in newborns with congenital diaphragmatic hernia. J Pediatr. 2010;156(3):495-497.e1.

58. Robertson JO, Criss CN, Hsieh LB, et al. Steroid use for refractory hypotension in congenital diaphragmatic hernia. Pediatr Surg Int. 2017;33(9):981-987.

59. Geggel RL, Murphy JD, Langleben D, et al. Congenital diaphragmatic hernia: arterial structural changes and persistent pulmonary hypertension after surgical repair. J Pediatr. 1985 107(3):457-64.

60. West KW, Bengston K, Rescorla FJ, et al. Delayed surgical repair and ECMO improves survival in congenital diaphragmatic hernia. Ann Surg. 1992;216(4):454-460.

61. Wung JT, Sahni R, Moffitt ST, et al. Congenital diaphragmatic hernia: survival treated with very delayed surgery, spontaneous respiration, and no chest tube. J Pediatr Surg. 1995;30(3):406-409.

62. Reickert CA, Hirschl RB, Schumacher R, et al.Effect of very delayed repair of congenital diaphragmatic hernia on survival and extracorporeal life support use. Surgery. 1996;120(4):766-772.

63. Brown RA, Bösenberg AT. Evolving management of congenital diaphragmatic hernia. Paediatr Anaesth. 2007;17(8):713-719.

64. Bösenberg AT, Brown RA. Management of congenital diaphragmatic hernia. Curr Opin Anaesthesiol. 2008;21(3):323-331.

65. Barnhart DC, Jacques E, Scaife ER, et al. Split abdominal wall muscle flap repair vs patch repair of large congenital diaphragmatic hernias. J Pediatr Surg. 2012;47(1):81-86.

66. Takayama S, Sakai K, Fumino S, et al. An intra-amniotic injection of mesenchymal stem cells promotes lung maturity in a rat congenital diaphragmatic hernia model. Pediatr Surg Int. 2019;35(12):1353-1361.

67. Sananès N, Regnard $P$, Mottet N, et al. Evaluation of a new balloon for fetal endoscopic tracheal occlusion in the nonhuman primate model. Prenat Diagn. 2019;39(5):403-408.

68. Guner YS, Harting MT, Fairbairn K, et al. Outcomes of infants with congenital diaphragmatic hernia treated with venovenous versus venoarterial extracorporeal membrane oxygenation: A propensity score approach. J Pediatr Surg. 2018;53(11):2092-2099.

69. Barbaro RP, Paden ML, Guner YS, et al. ELSO member centers. Pediatric Extracorporeal Life Support Organization Registry International Report 2016. ASAIO J. 2017;63(4):456-463. 